\title{
The impact of work design, autonomy support, and strategy on employee outcomes: A differentiated perspective on self-determination at work
}

\author{
Stefan T. Güntert
}

Published online: 1 June 2014

(C) Springer Science+Business Media New York 2014

\begin{abstract}
Drawing upon self-determination theory, this study tested different types of behavioral regulation as parallel mediators of the association between the job's motivating potential, autonomy-supportive leadership, and understanding the organization's strategy, on the one hand, and job satisfaction, turnover intention, and two types of organizational citizenship behaviors (OCB), on the other hand. In particular, intrinsic motivation and identified regulation were contrasted as idiosyncratic motivational processes. Analyses were based on data from 201 employees in the Swiss insurance industry. Results supported both types of self-determined motivation as mediators of specific antecedent-outcome relationships. Identified regulation, for example, particularly mediated the impact of contextual antecedents on both civic virtue and altruism OCB. Overall, controlled types of behavioral regulation showed comparatively weak relations to antecedents or consequences. The unique characteristics of motivational processes and potential explanations for the weak associations of controlled motivation are discussed.
\end{abstract}

Keywords Work motivation - Self-determination theory · Strategy · Organizational citizenship behaviors · Multiple mediation analysis

\section{Introduction}

Self-determination theory (SDT; cf. Deci and Ryan 2000) is a general approach to human motivation and personality that addresses the quality of motivation in addition to the

S. T. Güntert ( $\square)$

ETH Zurich, Weinbergstrasse 56/58, 8092 Zurich, Switzerland

e-mail: sguentert@ethz.ch quantity or intensity of motivation. SDT differentiates between several types of behavioral regulation that reflect either self-determination or control. This quality of motivation is regarded as an important predictor of favorable outcomes beyond a merely quantitative approach. Several studies have taken an SDT perspective on motivation in applied contexts as diverse as education, parenting, weight loss, practicing religion, volunteering, romantic relationships, or dental hygiene (cf. Deci and Ryan 2008, for an overview). For the context of work, Gagné and Deci (2005) developed a framework that conceptualizes the quality of motivation as linking characteristics of the work environment and individual differences to behavioral and attitudinal outcomes.

SDT postulates several distinct types of behavioral regulation that have unique characteristics beyond the overarching quality of self-determination versus control. However, most studies did not differentiate between these specific types of motivation. Drawing on SDT and the framework by Gagné and Deci (2005), in particular, the aim of this study was to focus on the idiosyncrasies of specific types of behavioral regulation. Specifically, the study examined the impact of work design, autonomysupportive leadership, and the perception of the organization's strategy on behavioral regulation and four outcomes: job satisfaction, turnover intention, and two types of organizational citizenship behavior (OCB; cf. Podsakoff et al. 2000). With respect to OCB and the organization's strategy, this study addressed novel correlates of the quality of motivation at work.

Self-determination theory

SDT as a general framework on human motivation and personality comprises several "mini-theories" (cf. Vansteenkiste 
et al. 2010). Integral feature of all SDT-based concepts is that they address the phenomenon of self-determination and volition versus control and alienation. Two mini-theories focus on the quality of behavioral regulation: the cognitive evaluation theory (CET) and the organismic integration theory (OIT).

CET centers on the concept of intrinsic motivation. An intrinsically motivated activity is done because the behavior is interesting and spontaneously satisfying. Intrinsic motivation is linked to the innate propensity of human beings to explore the environment, to shape their abilities, and to conquer optimal challenges. Emotions typically associated with intrinsic motivation are joy, interest, and excitement. This type of behavioral regulation represents the prototype of self-determined motivation: When intrinsically motivated, people experience a sense of choice and fully endorse the activity they are engaged in. A lot of research in the realm of CET has shown that intrinsic motivation can be undermined by extrinsic rewards, especially if these external contingencies are experienced as controlling (cf. the meta-analysis by Deci et al. 1999).

In contrast, extrinsically motivated activities are instrumental to some external outcome beyond the activity itself. However, extrinsic motivation is rather the counterpart than the opposite of intrinsic motivation. Although intrinsic motivation is the prototype of self-determined motivation, extrinsic motivation does not per se reflect control or the lack of self-determination. OIT introduces a differentiated view of extrinsic motivation: Extrinsic motivation can be regulated in an either controlled or selfdetermined way. OIT assumes that human beings possess the inherent tendency to internalize the regulation of behavior that has originally been under the control of external contingencies. Depending on the extent to which behavioral regulation has been internalized, people can experience choice and fully endorse the activity-which still remains extrinsically motivated. Along this process of internalization and integration, several types of behavioral regulation can be differentiated:

External regulation represents the most controlled type of extrinsic motivation; immediate contingencies such as rewards or (the avoidance of) punishments regulate the behavior. The "locus of causality" for the activity is perceived as external-that is, the activity is "seen as being brought about by events and pressures outside of one's integrated sense of self" (Deci and Ryan 1985, p. 111).

Introjected regulation describes the type of motivation that occurs when the regulation of a behavior is not dependent on external contingencies, but has already been internalized to a certain extent. The behavior is regulated by feelings of guilt and shame; self-worth is contingent on showing the behavior. Although the behavior is under "internal control", the perceived locus of causality is still external; the behavior is not endorsed by the core sense of self.

Identified regulation and integrated regulation denote types of motivation that are experienced as volitional and self-determined. The behavior is regulated by well-internalized goals and values that either are considered as personally important or reflect the individual's integrated sense of self, respectively. The perceived locus of causality for the respective activity is internal: The activity is "congruent with or emanates from one's sense of self" (Deci and Ryan 1985, p. 111). Several instruments assessing the quality of behavioral regulation do not measure integrated regulation; previous research had difficulty in keeping integrated regulation as a separate facet independent of identified regulation and intrinsic motivation (cf. Gagné et al. 2010).

Beyond intrinsic motivation and the various types of extrinsic motivation, amotivation represents the lack of motivation or the absence of intentional regulation of behavior. Some researchers did not address this type of motivation in their studies because it represents low quantity or intensity of motivation rather than the quality perspective on motivation that is characteristic of SDT (cf. Fernet et al. 2012).

Bringing CET and OIT together, these different types of behavioral regulation can be ordered along a continuum ranging from controlled to self-determined motivation (please note that some researchers use the term "autonomous" instead of "self-determined" without conceptual difference). Self-determined motivation comprises both intrinsic motivation and well-internalized regulation of extrinsic motivation, whereas external and introjected regulation of extrinsic motivation is experienced as controlled motivation; amotivation stands for the lack of intentional regulation. Given this continuum, several studies formed a "relative autonomy index" (RAI) integrating the different types of behavioral regulation, for example, based on the formula: Intrinsic*2 + Identified - Introjected - External*2 (e.g., Trépanier et al. 2013).

Intrinsic motivation and the internalization of extrinsic motivation are affected by similar contextual factors. A concept that helped integrating these parallel findings was the proposition of three basic psychological needs (Deci and Ryan 2000). The innate needs for autonomy, competence, and relatedness, are regarded as nutriments of psychological growth and integrity. Conditions supportive of these needs will foster both intrinsic motivation and the internalization of extrinsic motivation. On the contrary, thwarting basic psychological needs is assumed to undermine intrinsic motivation and forestall the internalization process. Consequently, both types of self-determined motivation reflect human flourishing, are accompanied by 
Fig. 1 Multiple mediation model conceptualizing five types of behavioral regulation as parallel mediators of antecedent-outcome links. The alternative representations illustrate other ways to examine the quality of motivation as a mediating process: first, by using composite scores for self-determination (combining intrinsic motivation and identified regulation) and control (combining introjected and external regulation); second, by forming a relative autonomy index (RAI). Dashed arrows represent direct paths linking antecedents to outcomes
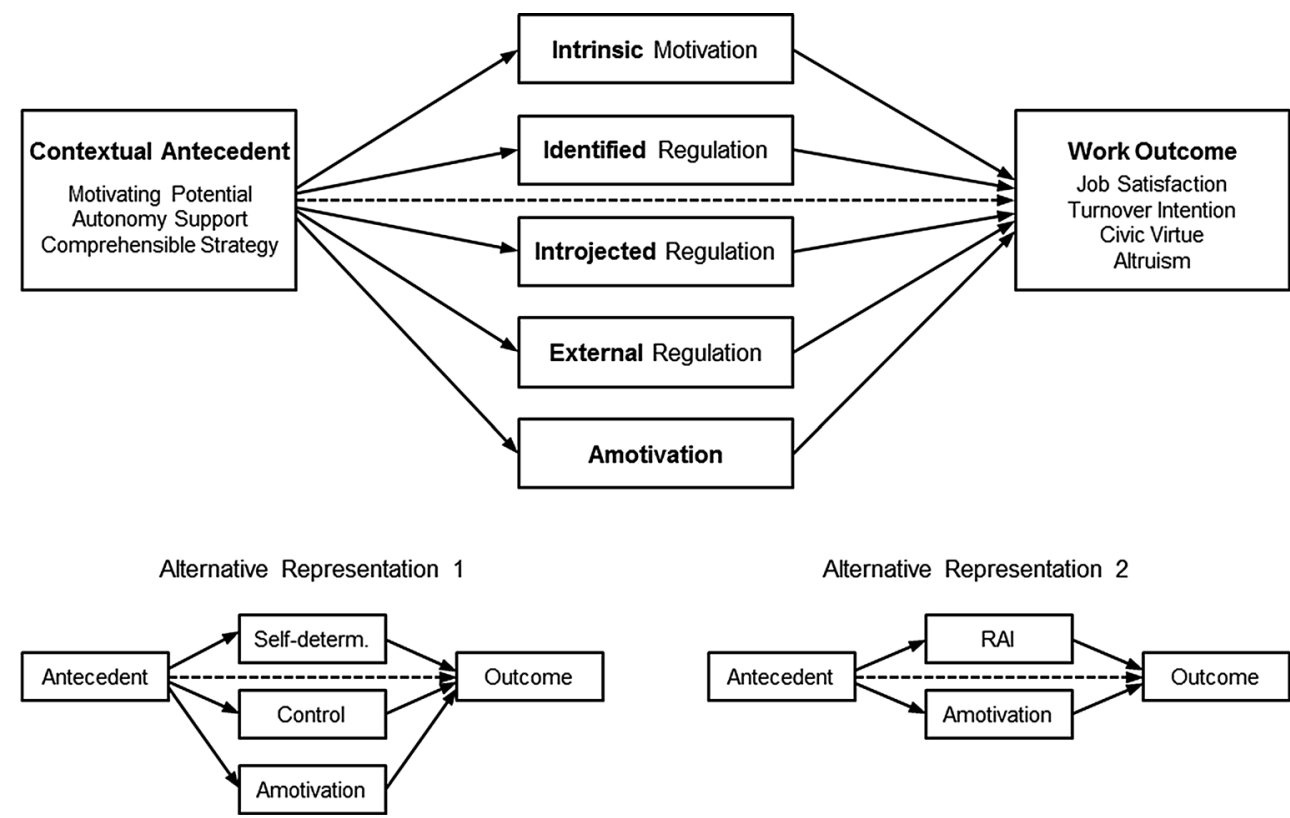

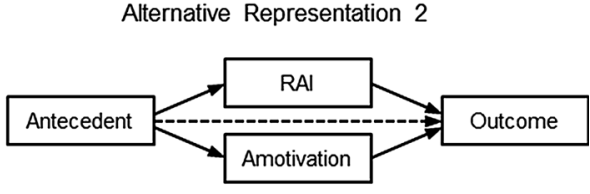

the experience of volition, and are associated with a variety of favorable outcomes. On the contrary, controlled motivation is presumed to obstruct personal growth.

Despite the similarities, CET and OIT contribute unique ideas to the understanding of human motivation. The unique aspect of well-internalized extrinsic motivation in contrast to intrinsic motivation is that it refers to the necessity of carrying out activities that are instrumental to a goal external of the activity itself. The activity itself might be boring and far from intrinsically motivating. If, however, the respective goal or value is endorsed by the integrated sense of self, the unpleasant activity can be regulated in a self-determined way. In the following, SDT's application to the context of work and organizations is presented.

Quality of behavioral regulation in the context of work

The basic assumptions about the quality of behavioral regulation and its correlates have been supported in various applied contexts such as physical education (e.g., Pelletier et al. 2001) and health care (e.g., Williams et al. 2009). Gagné and Deci (2005) applied SDT's perspective to the context of work and organizations. The extent to which behavior is regulated in a self-determined versus controlled way is conceptualized as a variable that mediates the impact of both contextual factors and individual differences on work outcomes. Figure 1 illustrates the quality of behavioral regulation as a mediating process. In addition to the multiple mediation model tested in this study two alternative representations of the quality of motivation are displayed.
Contextual factors that were specifically addressed as antecedents of the quality of motivation are the job's content and context, and autonomy support. Previous research has shown that job characteristics such as job feedback and task significance were positively related to self-determined motivation (cf. Gagné et al. 1997; Richer et al. 2002). Similarly, autonomy-supportive leadership was confirmed as a positive predictor of self-determined types of behavioral regulation (cf. Gillet et al. 2013; Kuvaas 2009; Otis and Pelletier 2005).

It is important to note that SDT does not suggest that the quality of behavioral regulation is an important predictor of every type of work outcome. For simple repetitive tasks, the mere quantity of motivation-even if regulated in a controlled way-may suffice as a predictor of performance (cf. Gagné and Deci 2005). The quality of motivation is rather expected to affect attitudinal outcomes (e.g., organizational commitment and job satisfaction), well-being, complex and non-routine performance, creativity, and behavior such as OCB that goes beyond immediate obligations.

Several studies have reported positive associations between self-determined types of behavioral regulation and various outcomes such as job satisfaction (Gillet et al. 2013; Lam and Gurland 2008; Richer et al. 2002), organizational commitment (Gagné et al. 2008), turnover intentions (Gillet et al. 2013; Otis and Pelletier 2005), selfrated performance (Kuvaas 2009), burnout (Fernet et al. 2004, 2012), somatic symptoms (Otis and Pelletier 2005), and citizenship (Tremblay et al. 2009).

Studies that addressed amotivation generally reported negative associations with favorable outcomes (e.g., 
Tremblay et al. 2009). Controlled motivation, however, showed less consistent correlational patterns. In general, weak and insignificant correlations prevail (cf. Bidee et al. 2012; Gagné et al. 2010). In particular, some studies found positive associations between introjected regulation and favorable outcomes such as work engagement (van Beek et al. 2012), satisfaction, commitment, and low turnover intention (Tremblay et al. 2009). However, a study by Fernet (2011) presented correlations in line with SDT assumptions: With respect to three work roles of school principals, intrinsic motivation and identified regulation were negatively related to burnout and positively related to both work satisfaction and occupational commitment; amotivation, external regulation, and-with only few exceptions-introjected regulation showed the reverse pattern.

Overall, most studies either formed composite scores for self-determined and controlled motivation or used indices such as the RAI, but did not investigate differential correlates of intrinsic motivation versus well-internalized extrinsic motivation. Gagné and Deci (2005) suggested this differentiated perspective in order to advance SDT as a model of work motivation.

\section{The present study}

The present study expected valuable insight into the motivational processes if the conceptual idiosyncrasy of all types of behavioral regulation was addressed. In so doing, this study addressed the question "how intrinsic motivation versus well-internalized extrinsic motivation will be differentially predictive in the workplace" (Gagné and Deci 2005, p. 348). Although Gagné and Deci proposed that OCB should be affected by the quality of motivation at work, this outcome has been given only scarce attention (one exception being the study by Tremblay et al. 2009). Thus, the present study focused specifically on two types of OCB: civic virtue and altruism. Additionally, job satisfaction and turnover intention were studied as work outcomes. With respect to antecedents of behavioral regulation, this study addressed work design and autonomy-supportive leadership trying to replicate earlier findings. Additionally, understanding the organization's strategy was suggested as an antecedent referring to the level of the organization as a whole.

In the following, this study's hypotheses are presented with respect to (a) the link between antecedents and behavioral regulation, (b) the link between behavioral regulation and work outcomes, and (c) behavioral regulation as a mediating process.

Work design is expected to be an important predictor of self-determined motivation. Hackman and Oldham (1976) considered "internal motivation" as an essential outcome of jobs that score high on the five core dimensions their job characteristics model described hereafter. Well-designed jobs offer interesting and challenging tasks that cover a complete and coherent range of activities that employees can identify with. They also provide choice and informational feedback that is designed into the task itself. Furthermore, jobs that are significant to other people's lives clearly demonstrate why it is important to show effort at one's work. The integration of all these job characteristics-that is, the job's "motivating potential"- - should foster intrinsic motivation, and facilitate the internalization of work-related goals and values. In the context of voluntary work, the job's motivating potential was associated with higher levels of intrinsic motivation and identified regulation (Millette and Gagné 2008).

Autonomy-supportive leadership has been studied extensively as an antecedent of self-determination and basic need satisfaction at work (cf. Baard et al. 2004). In addition, understanding the organization's strategy has been included as antecedent of motivation. This aspect refers to the relationship between employees and the organization as a whole. Providing a meaningful rationale has been identified as an important feature supporting the internalization of extrinsic motivation (cf. Deci et al. 1994). If employees are able to understand the organization's strategy, the goals of specific work activities should be internalized more easily. To the contrary, intrinsic motivation should be undermined if the strategy cannot be understood. Explaining the organization's strategy might be regarded as one of the supervisor's tasks. However, given the uncertainties in the insurance industry at the time of this study, employees of organizations operating around the globe might be well aware of their immediate supervisors' restricted capabilities. Therefore, it was expected that autonomy support would not fully capture the "providing a rationale" factor for success.

Taken together, all antecedents were expected to foster intrinsic motivation and support the internalization of extrinsic motivation:

Hypothesis 1 The job's motivating potential, autonomysupportive leadership, and understanding the organization's strategy are positively associated with intrinsic motivation and identified regulation, and negatively associated with introjected regulation, external regulation, and amotivation.

With respect to work outcomes, this study focused, in particular, on OCB as an important outcome in work organizations, and tried to replicate previous findings that linked the quality of motivation to job satisfaction and turnover intention. OCBs are given spontaneously and reach beyond what can be formally required by the organization. Organizations greatly benefit from proactive 
employees who voluntarily share innovative ideas, actively participate in meetings, or offer assistance to co-workers. Gagné and Deci (2005) assumed that OCB-as a voluntary work behavior - would be similarly affected by the quality of motivation as volunteering and prosocial behavior. In this study, two types of OCB were investigated: civic virtue, that is, behaviors directed at the organization itself (e.g., participating in meetings, sharing one's ideas); and altruism, that is, behaviors directed at co-workers (e.g., helping people with work-related problems).

The present study proposed:

Hypothesis 2 Intrinsic motivation and identified regulation are positively related to job satisfaction, low turnover intention, civic virtue, and altruism; conversely, introjected regulation, external regulation, and amotivation are negatively related to these work outcomes.

Gagné and Deci (2005) suggested the quality of behavioral regulation as a process that mediates the impact of contextual factors on work outcomes. Most research that tested for mediation confirmed behavioral regulation at least as a partial mediator of antecedent-outcome relationships. Intrinsic motivation, for example, mediated the impact of supervisor support on self-rated performance (Kuvaas 2009). A composite index of relative self-determination mediated the impact of autonomy support on future work intentions (Otis and Pelletier 2005), and the impact of job characteristics on work satisfaction (Richer et al. 2002). None of these studies, however, addressed the different types of behavioral regulation as parallel mediators.

Previous research has reported significant associations between contextual antecedents and work outcomes that were addressed by this study. The motivating potential of jobs has been linked to job satisfaction, low turnover intention (Humphrey et al. 2007), and both civic virtue and altruism OCB (Podsakoff et al. 2000). Autonomysupportive leadership has been positively associated with future work intentions (Otis and Pelletier 2005) and satisfaction at work (Moreau and Mageau 2011). Transformational leadership, which is related to the idea of an autonomy-supportive leadership, has been linked to OCB (Podsakoff et al. 2000). There are also constructs sharing some similarities with the idea of understanding the organization's strategy: Value congruence has been shown to relate to satisfaction, low turnover intention, and OCB (Cable and DeRue 2002). Taken together, the different types of behavioral regulation should turn out as substantial mediators of antecedent-outcome relationships:

Hypothesis 3a The job's motivating potential, autonomy-supportive leadership, and understanding the organization's strategy positively relate to job satisfaction, low turnover intention, civic virtue, and altruism.
Hypothesis 3b The different types of behavioral regulation mediate the link between contextual antecedents and work outcomes.

Despite various similarities, there are significant conceptual idiosyncrasies of intrinsic motivation and wellinternalized extrinsic motivation. Gagné and Deci (2005) suggested that "autonomous extrinsic motivation will be more effective in predicting persistence on uninteresting, but effort-driven tasks, whereas intrinsic motivation will be more effective in predicting persistence on interesting tasks." (p. 348). They related to a study by Losier and Koestner (1999) showing that well-internalized extrinsic motivation was the best predictor of activities that were personally meaningful, but not necessarily fun, and, thus, required personal commitment and discipline.

Against this background, the present study proposed that the impact of contextual antecedents on OCB would be mediated by well-internalized extrinsic motivation, specifically. Identified regulation should be, in particular, predictive of the extra effort displayed by civic virtue and altruism. These behaviors reflect the awareness that some action - that is not necessarily fun or interesting - must be taken, in order to improve the organization or to help coworkers. In contrast, job satisfaction as an attitudinal outcome reflects - to a considerable extent-the pleasure derived from the activity and, thus, should be affected by intrinsic motivation, in particular. Overall, previous research has found that intrinsic motivation-the prototype of self-determination-was more strongly than identified regulation associated with favorable attitudinal outcomes (cf. Gagné et al. 2010; Tremblay et al. 2009). Taken together, intrinsic motivation and identified regulation were hypothesized as differential mediators:

Hypothesis 4a The impact of contextual antecedents (i.e., the job's motivating potential, autonomy-supportive leadership, and understanding the organization's strategy) on civic virtue and altruism is mediated more strongly by identified regulation than by intrinsic motivation.

Hypothesis 4b The impact of contextual antecedents on job satisfaction is mediated more strongly by intrinsic motivation than by identified regulation.

\section{Methods}

Participants and procedure

People working for so-called general agencies in the Swiss insurance industry were invited to complete an anonymous online survey. General agencies are the local offices of insurance companies in contrast to the companies' 
headquarters; their services typically involve effecting insurance policies and managing claims. This type of work "in the field" shares unique challenges across the boundaries of single insurance companies. Supported by a professional association of general agencies, invitation e-mails were sent to "general agents" (i.e., the directors of general agencies) who were asked to answer the survey themselves and to forward the invitation to other people working at the general agency.

In total, data were obtained from 219 people working in the German-speaking part of Switzerland. The data of 51 participants contained missing values. Eight participants did not answer the leadership items because they had either no or more than one immediate supervisor; these data were excluded. With respect to the data provided by the remaining 43 participants, imputation of missing values was applied if there was only one missing value among the items pertaining to a scale of at least four items. For imputation, the EM (expectation-maximization) algorithm implemented in SPSS was applied. In this way, the data of 33 people were completed by imputation, resulting in a final data base provided by 201 participants. Overall, the extent of missing data was very small; the 33 individual data completed by imputation had missing values with respect to 1.7 items on average. Seventy-eight percent of the participants were men, $20 \%$ women. The median age was 42.9 years (first quartile: 34.2 years; third quartile: 50.4 years; age was measured using categories comprising 5 years).

\section{Measures}

All items except for the behavioral regulation items were answered on a 5-point scale from 1 (strongly disagree) to 5 (strongly agree).

\section{Work design}

Using the Work Design Questionnaire (WDQ; Morgeson and Humphrey 2006) five task characteristics were measured: (1) autonomy (four items in total; all three decision-making autonomy items, e.g., "The job allows me to make a lot of decisions on my own," and the work methods autonomy item "The job allows me to decide on my own how to go about doing my work"); (2) task variety (four items, e.g., "The job involves doing a number of different things"); (3) task significance (four items, e.g., "The results of my work are likely to significantly affect the lives of other people"); (4) task identity (four items, e.g., "The job is arranged so that I can do an entire piece of work from beginning to end"); (5) feedback from the job (three items, e.g., "The job itself provides me with information about my performance"). Averaging the five scores, an overall index for the job's "motivating potential" was formed (Cronbach's $\alpha=.84$ ).

\section{Autonomy-supportive leadership}

The Work Climate Questionnaire (Baard et al. 2004), consisting of six items (e.g., "My manager listens to how I would like to do things"; Cronbach's $\alpha=.92$ ), was used to measure autonomy-supportive leadership.

\section{Organizational strategy}

The single item "The organization's strategy is comprehensible to me" addressed the issue whether employees understand the strategy of the organization.

\section{Behavioral regulation}

The revised version of the Motivation at Work Scale (MAWS-R; Gagné et al. 2010, 2012) differentiates between five types of behavioral regulation. External regulation is represented by six items, introjected regulation by four items, and the remaining three types of behavioral regulation by three items each. All items represent answers to the question "Why do you or would you put efforts into your job?" and are rated on a scale from 1 (not at all for this reason) to 7 (exactly for this reason). Sample items are: "Because the work I do is interesting" for intrinsic motivation (Cronbach's $\alpha=.93$ ); "Because I personally consider it important to put efforts in this job" for identified regulation $(\alpha=.70)$; "Because otherwise I will feel ashamed of myself" for introjected regulation $(\alpha=.66)$; "To avoid being criticized by others (e.g., supervisor, colleagues, family, clients)" for external regulation ( $\alpha=.79$ ); and "I do little because I don't think this work is worth putting efforts into" for amotivation $(\alpha=.80)$.

\section{Job satisfaction}

Job satisfaction was measured with four items (Cronbach's $\alpha=.89$ ) adapted from Saks and Ashforth (1997), for example, "All in all, I am satisfied with my job," and from Lauver and Kristof-Brown (2001), for example, "I find real enjoyment in my work."

\section{Turnover intention}

Two items adapted from Colarelli (1984) measured turnover intention (Cronbach's $\alpha=.85$ ): "I frequently think of quitting my job," and "I am planning to search for a new job during the next 12 months."

\section{Civic virtue and altruism $O C B$}

The facets of civic virtue and altruism were measured with 4-item scales based on Niehoff and Moorman (1993). 
Table 1 Means, standard deviations, intercorrelations and internal consistency for all variables

\begin{tabular}{|c|c|c|c|c|c|c|c|c|c|c|c|c|c|c|}
\hline Variable & M & SD & 1 & 2 & 3 & 4 & 5 & 6 & 7 & 8 & 9 & 10 & 11 & 12 \\
\hline \multicolumn{15}{|l|}{ Contextual antecedents } \\
\hline 1. Motivating potential ${ }^{\mathrm{a}}$ & 4.16 & 0.53 & .84 & & & & & & & & & & & \\
\hline 2. Autonomy-supportive leadership & 4.02 & 0.81 & .41 & .92 & & & & & & & & & & \\
\hline 3. Understanding organization's strategy & 3.65 & 1.20 & .35 & .36 & - & & & & & & & & & \\
\hline \multicolumn{15}{|l|}{ Behavioral regulation } \\
\hline 4. Intrinsic motivation & 5.99 & 0.95 & .64 & .32 & .30 & .93 & & & & & & & & \\
\hline 5. Identified regulation & 5.71 & 0.88 & .56 & .24 & .36 & .71 & .70 & & & & & & & \\
\hline 6. Introjected regulation & 4.48 & 1.16 & -.06 & -.13 & -.08 & .05 & .14 & .66 & & & & & & \\
\hline 7. External regulation & 3.80 & 1.23 & -.12 & -.08 & -.10 & -.22 & -.03 & .51 & .79 & & & & & \\
\hline 8. Amotivation & 1.33 & 0.70 & -.34 & -.11 & -.23 & -.47 & -.43 & -.04 & .19 & .80 & & & & \\
\hline \multicolumn{15}{|l|}{ Work outcomes } \\
\hline 9. Job satisfaction & 4.25 & 0.66 & .56 & .38 & .44 & .76 & .62 & -.14 & -.20 & -.44 & .89 & & & \\
\hline 10. Turnover intention & 1.98 & 1.18 & -.36 & -.39 & -.58 & -.45 & -.37 & .18 & .21 & .35 & -.61 & .85 & & \\
\hline 11. Civic virtue & 4.19 & 0.56 & .42 & .16 & .16 & .38 & .47 & -.13 & -.12 & -.30 & .36 & -.17 & .76 & \\
\hline 12. Altruism & 4.19 & 0.58 & .25 & .07 & .15 & .37 & .48 & -.02 & -.08 & -.25 & .34 & -.12 & .56 & .70 \\
\hline
\end{tabular}

$N=201$. Internal consistency (i.e., Cronbach's coefficient $\alpha$ ) is displayed in the diagonal (if applicable). All measures are on a scale from 1 to 5 , except for measures $9-13$, which are on a scale from 1 to 7

Level of significance concerning the correlations: $p<.10$, if $.12 \leq$ abs $(r) \leq .14 ; p<.05$, if $.15 \leq$ abs $(r) \leq .18 ; p<.01$, if abs $(r) \geq .19$

${ }^{a}$ This score was formed as the average of the scores for autonomy, variety, significance, identity, and feedback from the job

Sample items are "I attend and participate in meetings regarding the organization" for civic virtue (Cronbach's $\alpha=.76)$ and "I willingly give my time to help others with work-related problems" for altruism $(\alpha=.70)$.

\section{Results}

\section{Bivariate associations}

The means, standard deviations, reliabilities, and the intercorrelations of all variables are presented in Table 1 . Hypotheses 1 and 2 refer to bivariate associations between the quality of behavioral regulation and variables that are considered as antecedents or consequences, respectively. Hypothesis 1 was partially supported. Intrinsic motivation and identified regulation showed positive associations with all contextual antecedents-ranging from $r=.24, p<.01$, to $r=.64, p<.01$. Amotivation showed negative associations with the job's motivating potential $(r=-.34$, $p<.01)$ and understanding the organization's strategy $(r=-.23, p<.01)$, but was not significantly related to autonomy-supportive leadership $(r=-.11, n s)$. Introjected regulation and external regulation, however, were not significantly related to contextual antecedents-with correlations ranging from $r=-.13$ to $r=-.06$.

In support of Hypothesis 2, both intrinsic motivation and identified regulation were positively related to job satisfaction, civic virtue, and altruism, and negatively related to turnover intention-with the absolute values of $r$ ranging from abs $(r)=.37, p<.01$, to abs $(r)=.76$, $p<.01$. As hypothesized, amotivation showed the reverse correlational pattern-with $r$ ranging from abs $(r)=.25$, $p<.01$, to abs $(r)=.44, p<.01$. In contrast, the associations between controlled types of behavioral regulation and work outcomes only partially supported Hypothesis 2 . External regulation was significantly related only to job satisfaction $(r=-.20, p<.01)$ and turnover intention $(r=.21, p<.01)$; and introjected regulation was only positively associated with turnover intention $(r=.18$, $p<.05$ ).

Hypothesis $3 \mathrm{a}$-concerning the relationships between contextual antecedents and work outcomes-was supported, with only one exception: The correlation between autonomy-supportive leadership and altruism was not statistically significant $(r=.07, n s)$.

Multiple mediation analysis

For each antecedent-outcome relationship, multiple mediator models were analyzed using the rationale recommended by Preacher and Hayes (2008). Multiple mediation analysis allows for testing and comparing specific indirect effects. These specific effects represent a variable's unique ability to mediate a certain association controlling for other parallel mediators. In advance of these analyses, the impact 
Table 2 Multiple mediation analyses: total, direct, and indirect effects of contextual antecedents on work outcomes

\begin{tabular}{|c|c|c|c|c|c|c|c|c|c|c|c|c|}
\hline \multirow[t]{4}{*}{ Antecedent/effect } & \multicolumn{12}{|c|}{ Work outcome } \\
\hline & \multicolumn{3}{|c|}{ Job satisfaction } & \multicolumn{3}{|c|}{ Turnover intention } & \multicolumn{3}{|c|}{ Civic virtue } & \multicolumn{3}{|l|}{ Altruism } \\
\hline & \multirow{2}{*}{$\begin{array}{l}\text { Point } \\
\text { Estimate }\end{array}$} & \multicolumn{2}{|c|}{$95 \% \mathrm{CI}$} & \multirow{2}{*}{$\begin{array}{l}\text { Point } \\
\text { Estimate }\end{array}$} & \multicolumn{2}{|c|}{$95 \% \mathrm{CI}$} & \multirow{2}{*}{$\begin{array}{l}\text { Point } \\
\text { Estimate }\end{array}$} & \multicolumn{2}{|c|}{$95 \% \mathrm{CI}$} & \multirow{2}{*}{$\begin{array}{l}\text { Point } \\
\text { Estimate }\end{array}$} & \multicolumn{2}{|c|}{$95 \% \mathrm{CI}$} \\
\hline & & LL & UL & & LL & UL & & LL & UL & & LL & UL \\
\hline \multicolumn{13}{|l|}{ Motivating potential } \\
\hline Total effect & 0.69 & 0.55 & 0.84 & -0.81 & -1.10 & -0.52 & 0.44 & 0.31 & 0.57 & .27 & 0.12 & 0.42 \\
\hline Direct effect & 0.13 & -0.02 & 0.27 & -0.26 & -0.62 & 0.10 & 0.26 & 0.09 & 0.42 & -0.05 & -0.22 & 0.13 \\
\hline Total indirect effect & 0.57 & 0.44 & 0.71 & -0.55 & -0.84 & -0.29 & 0.18 & 0.05 & 0.36 & 0.32 & 0.20 & 0.46 \\
\hline \multicolumn{13}{|l|}{ Indirect effect via } \\
\hline (A) Intrinsic & 0.47 & 0.31 & 0.63 & -0.33 & -0.66 & -0.02 & -0.09 & -0.25 & 0.05 & -0.00 & -0.19 & 0.17 \\
\hline (B) Identified & 0.06 & -0.05 & 0.19 & -0.07 & -0.36 & 0.18 & 0.24 & 0.11 & 0.40 & 0.30 & 0.15 & 0.49 \\
\hline (C) Introjected & 0.01 & -0.01 & 0.04 & -0.02 & -0.10 & 0.02 & 0.01 & -0.01 & 0.05 & 0.00 & -0.01 & 0.03 \\
\hline (D) External & -0.00 & -0.03 & 0.02 & -0.01 & -0.10 & 0.03 & 0.00 & -0.02 & 0.03 & 0.01 & -0.01 & 0.04 \\
\hline (E) Amotivation & 0.04 & -0.01 & 0.10 & -0.12 & -0.29 & -0.02 & 0.03 & -0.02 & 0.08 & 0.01 & -0.05 & 0.06 \\
\hline Contrast: A minus B & 0.41 & 0.16 & 0.64 & -0.26 & -0.77 & 0.29 & -0.33 & -0.60 & -0.09 & -0.30 & -0.66 & -0.01 \\
\hline Model $R^{2}$ & $.61 * * *$ & & & $.26 * * *$ & & & $.29 * * *$ & & & $.24 * * *$ & & \\
\hline AR1 ${ }^{\mathrm{a}}$ : Total indir. eff. & 0.53 & 0.41 & 0.67 & -0.52 & -0.81 & -0.27 & 0.21 & 0.08 & 0.39 & 0.35 & 0.25 & 0.48 \\
\hline AR1: Model $R^{2}$ & $.58 * * *$ & & & $.25 * * *$ & & & $.25 * * *$ & & & $.21 * * *$ & & \\
\hline AR2 ${ }^{\mathrm{b}}$ : Total indir. eff. & 0.28 & 0.20 & 0.40 & -0.41 & -0.60 & -0.24 & 0.13 & 0.04 & 0.24 & 0.15 & 0.07 & 0.24 \\
\hline AR2: Model $R^{2}$ & $.48 * * *$ & & & $.24 * * *$ & & & $.23 * * *$ & & & $.12 * * *$ & & \\
\hline \multicolumn{13}{|c|}{ Autonomy-supportive leadership } \\
\hline Total effect & 0.31 & 0.21 & 0.42 & -0.57 & -0.76 & -0.38 & 0.11 & 0.01 & 0.20 & 0.05 & -0.05 & 0.15 \\
\hline Direct effect & 0.12 & 0.04 & 0.19 & -0.40 & -0.59 & -0.22 & 0.02 & -0.07 & 0.11 & -0.04 & -0.13 & 0.05 \\
\hline Total indirect effect & 0.19 & 0.10 & 0.30 & -0.17 & -0.30 & -0.07 & 0.09 & 0.04 & 0.16 & 0.09 & 0.03 & 0.16 \\
\hline \multicolumn{13}{|l|}{ Indirect effect via } \\
\hline (A) Intrinsic & 0.17 & 0.09 & 0.27 & -0.11 & -0.23 & -0.03 & 0.01 & -0.04 & 0.05 & 0.00 & -0.05 & 0.05 \\
\hline (B) Identified & 0.01 & -0.02 & 0.05 & -0.01 & -0.11 & 0.05 & 0.07 & 0.02 & 0.13 & 0.08 & 0.04 & 0.17 \\
\hline (C) Introjected & 0.00 & -0.01 & 0.02 & -0.01 & -0.07 & 0.01 & 0.01 & 0.00 & 0.04 & 0.00 & -0.01 & 0.02 \\
\hline (D) External & 0.00 & -0.01 & 0.01 & -0.01 & -0.06 & 0.01 & 0.00 & -0.01 & 0.02 & 0.00 & -0.00 & 0.02 \\
\hline (E) Amotivation & 0.01 & -0.00 & 0.03 & -0.03 & -0.09 & -0.00 & 0.01 & -0.00 & 0.03 & 0.00 & -0.01 & 0.02 \\
\hline Contrast: A minus B & 0.16 & 0.07 & 0.27 & -0.10 & -0.27 & 0.05 & -0.06 & -0.18 & 0.01 & -0.08 & -0.21 & -0.00 \\
\hline Model $R^{2}$ & $.62 * * *$ & & & $.31 * * *$ & & & $.25 * * *$ & & & $.24 * * *$ & & \\
\hline AR1: Total indir. eff. & 0.18 & 0.09 & 0.28 & -0.16 & -0.29 & -0.07 & 0.09 & 0.05 & 0.16 & 0.10 & 0.05 & 0.17 \\
\hline AR1: Model $R^{2}$ & $.59 * * *$ & & & $.31 * * *$ & & & $.22 * * *$ & & & $.21 * * *$ & & \\
\hline AR2: Total indir. eff. & 0.11 & 0.05 & 0.20 & -0.13 & -0.24 & -0.05 & 0.06 & 0.02 & 0.11 & 0.05 & 0.02 & 0.11 \\
\hline AR2: Model $R^{2}$ & $.45^{* * *}$ & & & $.30 * * *$ & & & $.16^{* * *}$ & & & $.11 * * *$ & & \\
\hline Understanding the organi & zation's strat & egy & & & & & & & & & & \\
\hline Total effect & 0.24 & 0.18 & 0.31 & -0.57 & -0.68 & -0.46 & 0.07 & 0.01 & 0.14 & 0.07 & 0.00 & 0.14 \\
\hline Direct effect & 0.12 & 0.07 & 0.17 & -0.47 & -0.59 & -0.36 & -0.02 & -0.08 & 0.04 & -0.02 & -0.08 & 0.05 \\
\hline Total indirect effect & 0.12 & 0.07 & 0.19 & -0.10 & -0.18 & -0.03 & 0.09 & 0.05 & 0.15 & 0.09 & 0.05 & 0.14 \\
\hline Indirect effect via & & & & & & & & & & & & \\
\hline (A) Intrinsic & 0.11 & 0.06 & 0.18 & -0.09 & -0.16 & -0.03 & -0.00 & -0.04 & 0.03 & -0.00 & -0.05 & 0.03 \\
\hline (B) Identified & 0.01 & -0.02 & 0.03 & 0.03 & -0.04 & 0.10 & 0.08 & 0.03 & 0.14 & 0.09 & 0.04 & 0.15 \\
\hline (C) Introjected & 0.00 & -0.00 & 0.02 & -0.01 & -0.05 & 0.01 & 0.01 & -0.00 & 0.03 & 0.00 & -0.00 & 0.02 \\
\hline (D) External & -0.00 & -0.01 & 0.00 & -0.00 & -0.03 & 0.01 & 0.00 & -0.01 & 0.01 & 0.00 & -0.00 & 0.02 \\
\hline (E) Amotivation & 0.01 & -0.00 & 0.03 & -0.03 & -0.08 & -0.00 & 0.01 & -0.00 & 0.03 & 0.00 & -0.02 & 0.02 \\
\hline Contrast: A minus B & 0.10 & 0.04 & 0.19 & -0.11 & -0.25 & -0.01 & -0.08 & -0.17 & -0.02 & -0.09 & -0.20 & -0.02 \\
\hline Model $R^{2}$ & $.64 * * *$ & & & $.45 * * *$ & & & $.25 * * *$ & & & $.24 * * *$ & & \\
\hline AR1: Total indir. eff. & 0.14 & 0.08 & 0.20 & -0.11 & -0.18 & -0.06 & 0.08 & 0.05 & 0.13 & 0.08 & 0.05 & 0.12 \\
\hline
\end{tabular}


Table 2 continued

\begin{tabular}{|c|c|c|c|c|c|c|c|c|c|c|c|c|}
\hline \multirow[t]{4}{*}{ Antecedent/effect } & \multicolumn{12}{|c|}{ Work outcome } \\
\hline & \multicolumn{3}{|c|}{ Job satisfaction } & \multicolumn{3}{|c|}{ Turnover intention } & \multicolumn{3}{|c|}{ Civic virtue } & \multicolumn{3}{|l|}{ Altruism } \\
\hline & \multirow{2}{*}{$\begin{array}{l}\text { Point } \\
\text { Estimate }\end{array}$} & \multicolumn{2}{|c|}{$95 \% \mathrm{CI}$} & \multirow{2}{*}{$\begin{array}{l}\text { Point } \\
\text { Estimate }\end{array}$} & \multicolumn{2}{|c|}{$95 \% \mathrm{CI}$} & \multirow{2}{*}{$\begin{array}{l}\text { Point } \\
\text { Estimate }\end{array}$} & \multicolumn{2}{|c|}{$95 \% \mathrm{CI}$} & \multirow{2}{*}{$\begin{array}{l}\text { Point } \\
\text { Estimate }\end{array}$} & \multicolumn{2}{|c|}{$95 \% \mathrm{CI}$} \\
\hline & & LL & UL & & LL & UL & & LL & UL & & LL & UL \\
\hline AR1: Model $R^{2}$ & $.61 * * *$ & & & $.43 * * *$ & & & $.22 * * *$ & & & $.21 * * *$ & & \\
\hline AR2: Total indir. eff. & 0.09 & 0.05 & 0.15 & -0.10 & -0.16 & -0.05 & 0.05 & 0.03 & 0.10 & 0.05 & 0.02 & 0.08 \\
\hline AR2: Model $R^{2}$ & $.47 * * *$ & & & $.43 * * *$ & & & $.16^{* * *}$ & & & $.11 * * *$ & & \\
\hline \multicolumn{13}{|c|}{$\begin{array}{l}N=201 . C I \text { confidence intervals, bias-corrected and based on } k=5,000 \text { bootstrap samples, } L L \text { lower limit, } U L \text { upper limit, } A R \text { alternative } \\
\text { representation, indir. eff. indirect effect }\end{array}$} \\
\hline \multicolumn{13}{|c|}{$\begin{array}{l}\text { an this alternative representation of the quality of motivation as a mediating process, self-determined motivation (combining intrinsic moti- } \\
\text { vation and identified regulation), controlled motivation (combining introjected and external regulation), and amotivation were analyzed as } \\
\text { parallel mediators }\end{array}$} \\
\hline \multicolumn{13}{|c|}{$\begin{array}{l}\text { b In this alternative representation, the relative autonomy index (based on the formula: Intrinsic*2 }+ \text { Identified }- \text { Introjected }- \text { External } * 2 \text { ) and } \\
\text { amotivation were analyzed as parallel mediators }\end{array}$} \\
\hline$* * * p<.01$ & & & & & & & & & & & & \\
\hline
\end{tabular}

of multicollinearity was addressed. With the highest value being 2.81, variance inflation factors showed that our analyses were not biased by intercorrelations among the types of behavioral regulation.

With respect to all antecedent-outcome relationships, Table 2 presents point estimates and bias-corrected confidence intervals (based on 5,000 bootstrap samples) for total effects, direct effects, the total of all indirect effects, and specific indirect effects. In support of Hypothesis $3 \mathrm{~b}$, the total indirect effect mediated by the five types of behavioral regulation was statistically significant with respect to all antecedent-outcome relationships. For some relationships, the direct effect was not significantly different from zero, indicating that the antecedent's impact on the respective outcome was fully mediated by the motivational processes. Full mediation was found with respect to the motivating potential's impact on job satisfaction, turnover intention, and altruism. Furthermore, the impact of both autonomy-supportive leadership and understanding the organization's strategy on both types of OCB was fully mediated by the five types of behavioral regulation.

The total indirect effects were transmitted by specific types of behavioral regulation. With respect to all antecedent-outcome relationships, either the indirect effect via intrinsic motivation or the indirect effect via identified regulation was significant (cf. Hypotheses $4 a$ and $4 b$ below). Furthermore, amotivation mediated the impact of all three contextual antecedents on turnover intention. With respect to controlled types of motivation, there was only one specific indirect effect significant: Introjected regulation mediated the positive impact of autonomy-supportive leadership on civic virtue, controlling for all other parallel mediators.
Previous research often used either composite scores for self-determined and controlled motivation or formed indices such as the RAI. Therefore, two alternative representations of the quality of motivation were also examined as mediators (cf. Fig. 1): (a) alternative representation 1: selfdetermined motivation, controlled motivation, and amotivation as parallel mediators; and (b) alternative representation 2: the RAI and amotivation as parallel mediators. Total indirect effects and the amount of variance in outcomes accounted for by the respective mediation model are given in Table 2. Overall, the representation advocated by this study (i.e., the five-mediator model) explained considerably more variance than alternative representation 2 using the RAI. Compared to alternative representation 1, only the differences with respect to civic virtue and altruism were remarkable.

Contrasting intrinsic motivation and identified regulation

Although multicollinearity did not bias the analyses, intercorrelations among parallel mediators have to be considered when interpreting contrasts between two mediators: "Contrasts do not compare two mediators in their ability to mediate, but rather their unique abilities to mediate, above and beyond any other mediators or covariates in the model" (Preacher and Hayes 2008, p. 887). Examining the unique contribution of intrinsic motivation versus identified regulation was a particular goal of this study reflected by Hypotheses $4 \mathrm{a}$ and $4 \mathrm{~b}$.

The contrasts between indirect effects mediated by intrinsic motivation versus identified regulation are shown in Table 2 (rows labeled "Contrast: A minus B"). With 
only one exception (concerning the mediated impact of autonomy-supportive leadership on civic virtue), all contrasts supported Hypotheses $4 \mathrm{a}$ and $4 \mathrm{~b}$.

Hypothesis 4a was fully supported with regard to the mediated impact of the motivating potential on civic virtue and altruism, respectively: The indirect effects mediated by identified regulation $(b=0.24,95 \%$ CI $0.11-0.40$, and $b=0.30,95 \%$ CI $0.15-0.49$, respectively) were larger than the indirect effects via intrinsic motivation ( $b=-0.09,95 \% \mathrm{CI}-0.25$ to 0.05 , and $b=-0.00,95 \%$ CI -0.19 to 0.17 , respectively). Concerning the mediated impact of autonomy-supportive leadership on OCB, Hypothesis 4a was partially supported: With respect to civic virtue, the indirect effect mediated by identified regulation ( $b=0.07,95 \%$ CI $0.02-0.13$ ) was not significantly different from the indirect effect via intrinsic motivation $(b=0.01,95 \% \mathrm{CI}-0.04$ to 0.05$)$. However, the indirect effect on altruism mediated by identified regulation ( $b=0.08,95 \%$ CI 0.04-0.17) was larger than the indirect effect via intrinsic motivation $(b=0.00,95 \% \mathrm{CI}-0.05$ to 0.05). Finally, Hypothesis 4 a was supported with regard to the mediated impact of understanding the organization's strategy on civic virtue and altruism, respectively: The indirect effects mediated by identified regulation $(b=0.08,95 \%$ CI $0.03-0.14$, and $b=0.09,95 \%$ CI 0.04-0.15, respectively) were larger than the indirect effects via intrinsic motivation $(b=-0.00,95 \% \mathrm{CI}$ -0.04 to 0.03 , and $b=-0.00,95 \% \mathrm{CI}-0.05$ to 0.03 , respectively).

Hypothesis $4 \mathrm{~b}$ was fully supported with regard to the mediated impact of all contextual antecedents on job satisfaction. The indirect effects mediated by intrinsic motivation $(b=0.47,95 \% \mathrm{CI} 0.31-0.63$, for the motivating potential, $b=0.17$, $95 \%$ CI $0.09-0.27$, for autonomysupportive leadership, and $b=0.11,95 \%$ CI $0.06-0.18$, for understanding the organization's strategy) were significantly larger than the indirect effects via identified regulation $(b=0.06,95 \% \mathrm{CI}-0.05$ to $0.19, b=0.01$, $95 \% \mathrm{CI}-0.02$ to 0.05 , and $b=0.01,95 \% \mathrm{CI}-0.02$ to 0.03 , respectively).

\section{Discussion}

The present study examined different types of behavioral regulation conceptualized by SDT as variables mediating the impact of contextual factors on work outcomes. Based on the conceptual framework by Gagné and Deci (2005), the aim of the study was to replicate and extend previous research, with a particular focus on idiosyncrasies of intrinsic motivation versus well-internalized extrinsic motivation. The study addressed civic virtue and altruism OCB (in addition to job satisfaction and turnover intention) as consequences of behavioral regulation that have been given only little attention to date. Furthermore, understanding of the organization's strategy (in addition to work design and autonomy-supportive leadership) was examined as a novel antecedent of work motivation.

Hypotheses 1 and 2 referred to bivariate associations between the quality of motivation, on the one hand, and antecedents and consequences, on the other hand. With respect to intrinsic motivation, identified regulation, and amotivation, these hypotheses were fully supported, with only one exception (autonomy-supportive leadership was not significantly related to amotivation. However, none of the contextual antecedents was significantly related to either introjected or external regulation. External regulation was only associated with job satisfaction $(r=-.20$, $p<.05)$ and turnover intention $(r=.21, p<.05)$; introjected regulation was only related to turnover intention $(r=.18, p<.05)$.

Overall, this correlational pattern paralleled results of previous studies. Self-determined types of behavioral regulation typically showed positive associations with work design (cf. Millette and Gagné), autonomy support (cf. Gillet et al. 2013) and favorable work outcomes (cf. Gagné et al. 2010). Similarly, low correlations between controlled types of behavioral regulation and both autonomy support and work outcomes were reported by, for example, Gagné et al. (2012) and Tremblay et al. (2009).

It is worth noting that, in the present study, introjected regulation was "at least" not positively related to either contextual antecedents or favorable work outcomes. In contrast, van Beek et al. (2012) reported strong positive correlation between introjected regulation and work engagement. Similarly, Gagné et al. (2010) found that introjected regulation was positively associated with job satisfaction, and Tremblay et al. (2009) showed that introjection was positively related to job satisfaction and negatively associated with turnover intentions.

\section{Quality of behavioral regulation as a mediating process}

This study tested different types of behavioral regulation as parallel mediators of antecedent-outcome relationships. Overall, the proposed associations between contextual antecedents and work outcomes (Hypothesis 3a) were confirmed, with the exception of the link between autonomy-supportive leadership and altruism.

Multiple mediation analyses fully supported Hypothesis 3b: For all antecedent-outcome relationships, the indirect effects mediated by the five types of behavioral regulation were significant. This five-mediator representation was compared to two alternative representations: (a) using amotivation and composite scores for self-determined and controlled motivation, and (b) using amotivation and the 
RAI as mediators. Overall, the representation advocated by this study explained more variance in civic virtue and altruism than the first alternative representation. Compared to the second representation, the five-mediator model accounted for strikingly more variance in job satisfaction, civic virtue, and altruism.

The mediation analyses allowed for testing and comparing specific indirect effects carried by particular types of behavioral regulation. External regulation did not mediate any of the antecedent-outcome relationships, controlling for parallel mediators. Introjected regulation, however, mediated the positive impact of autonomy-supportive leadership on civic virtue. This finding confirmed basic assumptions about the nature of autonomy support. From an SDT perspective, autonomy support should not only foster intrinsic motivation and the internalization process, but also reduce the negative impact of controlling contingencies, both internally (introjected regulation) and externally (external regulation). The present study showed that autonomy-supportive leadership positively affected civic virtue because it reduced introjected regulation, which, in turn, would have decreased civic virtue. This result diverged from previous research that reported positive associations between autonomy support and introjected regulation (cf. Gagné et al. 2010; Tremblay et al. 2009).

Intrinsic motivation versus well-internalized extrinsic motivation

SDT and its mini-theories CET and OIT describe intrinsic motivation and the internalization of extrinsic motivation as distinct psychological processes. Thus, Hypotheses $4 \mathrm{a}$ and $4 \mathrm{~b}$ stated that identified regulation and intrinsic motivation would function differentially as mediators of antecedent-outcome relationships. The results clearly supported Hypothesis 4a: Except for the impact of autonomy-supportive leadership on civic virtue, all relationships between contextual antecedents and both types of OCB were mediated more strongly by identified regulation than by intrinsic motivation. Hypothesis $4 \mathrm{~b}$ was fully supported: The indirect effects of contextual antecedents on job satisfaction were more strongly mediated by intrinsic motivation than by identified regulation. Taken together, these results demonstrated that intrinsic motivation and wellinternalized extrinsic motivation are differentially predictive of specific work outcomes that reflect either the inherent pleasure or the personal relevance and necessity, respectively.

Remarkably, studies by van Beek et al. $(2011,2012)$ also demonstrated idiosyncrasies of intrinsic motivation and identified regulation: Both intrinsic motivation and identified regulation were positively related to work engagement; however, only identified regulation and both types of controlled motivation were positively associated with workaholism, whereas intrinsic motivation was unrelated to this outcome.

In the following, three issues will be further addressed: (a) potential explanations for controlled motivation's weak associations, (b) the value of motivational antecedents at the organizational level, and (c) future avenues for a differentiated perspective on work motivation.

\section{Controlled motivation at work}

Both types of controlled motivation showed comparatively weak associations with the antecedents and outcomes. This finding raises the question whether controlled types of behavioral regulation are a relevant aspect of the work experience at all.

SDT describes introjected regulation as a form of extrinsic motivation regulated by self-worth contingencies, which are experienced as internally controlling. Employees may pressure themselves towards specific outcomes either to avoid feelings of shame and guilt or to inflate their feelings of self-worth. Autonomy-supportive leadership may reduce this tendency to experience internal controland, actually, the present study showed that autonomy support's positive impact on civic virtue was mediated by reduced levels of introjection. Nevertheless, inter-individual differences with respect to personality or life aspirations may be more important antecedents of introjection than aspects of the immediate work environment.

External regulation showed noticeably low correlations with both antecedents and outcomes. The items for external regulation used in this study represent quite diverse aspects of external contingencies. Some of the MAWS-R items refer to social contingencies, that is, to supervisors, co-workers, clients, or the employee's family and friends as people whose reactions may become the external regulators of one's behavior at work. For practically any type of work, people can refer to one or more of these groups. However, caring about the reactions of the various agents does not have to be associated with the experience of external control. Clients, in particular, are not as "external" to one's work as, for example, parents are to a student's homework or peers are to a teenager's effort to lose weight. The significance of one's job for other people's lives represents an important job characteristic that has been linked to favorable attitudinal outcomes such as internal work motivation (cf. Humphrey et al. 2007). To the extent that co-workers and supervisors are seen as "clients inside the organization", similar considerations may apply. Therefore, rating other persons'- especially, the clients'approval as a relevant reason for putting effort into one's job does not necessarily imply an external perceived locus of causality. In sequence, the negative impact on, for example, job satisfaction, should not occur. 
Motivational antecedents at the organizational level

Although understanding the organization's strategy was measured by a single item, this organization-level predictor of behavioral regulation deserves particular attention. Understanding the strategy clearly aligns with SDT's proposition that providing a rationale is crucial for facilitating the internalization process. This is the first study that considered motivational antecedents beyond the "inner circle" of job content and employees' immediate social environment.

Similarly, Greguras and Diefendorff (2009) showed that different types of person-environment fit can be linked to basic need satisfaction at work. The person-organization fit referred to the relationship between the individual and the organization as a whole. Specified as value congruence, this type of fit was strongly related to satisfaction of the basic need for autonomy, which, in turn, has been linked to self-determined motivation in previous research (cf. Van den Broeck et al. 2010). Understanding the organization's strategy should significantly contribute to the experience of value congruence and to the favorable consequences thereof. Thus, addressing the relationship between employees and the organization as a whole represents a valuable route for future research.

\section{Expanding the differentiated perspective}

The present study showed that various types of behavioral regulation differentially mediated the impact of contextual antecedents on work outcomes. Specifically, intrinsic motivation and identified regulation held unique characteristics. Gagné and Deci (2005) proposed well-internalized extrinsic motivation to be more predictive of effortdriven tasks that are personally meaningful. Therefore, civic virtue and altruism were addressed as outcomes that should be affected specifically via identified regulation.

However, the idiosyncrasies of intrinsic motivation and well-internalized extrinsic motivation do not finish with the ability to predict work outcomes differentially. Both types of self-determined motivation represent unique motivational processes that can be affected by distinct features of the work environment; Gagné and Deci (2005), for example, pointed out that "people do not necessarily require structures, limits, or contingencies to maintain intrinsic motivation" (p. 339). In this study, understanding the organization's strategy was more strongly associated with identified regulation than intrinsic motivation. This contextual antecedent represents a good example of antecedents that are specifically relevant to the internalization of extrinsic motivation. Understanding the organization's strategy provides a rationale for putting effort into necessary activities, even if these are unpleasant.

Losier and Koestner (1999) examined differential associations of intrinsic motivation versus identified regulation in the context of political participation. Their conclusion and invitation to study "which environmental factors are uniquely associated with the promotion of identification rather than intrinsic motivation" (p. 296), has to be echoed with respect to the context of work and organizations.

\section{Limitations and future research}

The major limitations of this study concern the cross-sectional design and its reliance on self-report data alone. Future experimental and longitudinal studies should allow for testing the causality proposed by SDT. In the context of education, Jang et al. (2012), provided a longitudinal test of the assumption that the impact of teachers' autonomy support on student outcomes was mediated by the selfdetermined quality of motivation. Similarly, the effects of work design interventions and leadership training could be tracked longitudinally in an organizational setting. Future studies should also include peer or supervisor ratings of OCB and objective performance indicators.

Understanding the organization's strategy was measured by a single item only. Nevertheless, this aspect was included as an antecedent of behavioral regulation at the level of the organization. Future research may investigate other antecedents that address the relationship between the employee and the organization as a whole-for example, value congruence.

This study was conducted in the Swiss insurance industry during a period of increased uncertainty due to the financial crisis. Therefore, some effects might be partially attributed to specific characteristics of the sample. The strong impact of understanding the organization's strategy, for example, may not generalize to organizations operating under more predictable circumstances. As this study's focus on a specific industry raises the issue of generalizability, future research should systematically address different work areas and develop a framework of relevant boundary conditions.

This study confirmed the quality of motivation as an important mediating process explaining the link between contextual antecedents and work outcomes. Overall, the indirect effects via behavioral regulation were considerably strong. However, the fact that some direct effects were significant shows that there are alternative paths-beyond the quality of motivation. Future research may combine SDT with other approaches that conceptualize alternative mediators, such as the job demands-resources model (cf. Bakker and Demerouti 2007), which suggests a health impairment process in addition to a motivational process.

\section{Practical implications}

Practitioners should be aware that both intrinsic motivation and identified regulation are types of motivation that are significantly linked to a range of favorable work outcomes. 
This study showed that the internalization of extrinsic motivation was specifically predictive of civic virtue and altruism OCB. Work design, for example, offers avenues for enhancing intrinsic motivation and fostering the internalization process. Jobs rich in task variety and autonomy provide opportunities for personal growth and mastering optimal challenges. Jobs that significantly affect other people's lives provide a good rationale for showing effort at one's work activities, even if these are unpleasant. Besides enhancing the motivating potential of jobs, there is a great deal of interventions that can be directed towards the internalization of extrinsic motivation. Understanding of the organization's strategy was strongly associated with identified regulation. Although this study did not further investigate what makes an organization's strategy understandable, this finding draws attention to the fact that organizational practices are important facilitators of the internalization process-beyond work design and leadership.

\section{Conclusions}

This research showed how various types of motivation differentially mediated the impact of contextual antecedents on work outcomes. The findings encourage further investigating the complexity of motivational processes at work. Exploring the idiosyncrasies of different types of behavioral regulation promotes SDT as a model of work motivation and opens up new perspectives for supporting self-determination and reducing control in the workplace.

\section{References}

Baard, P. P., Deci, E. L., \& Ryan, R. M. (2004). Intrinsic need satisfaction: A motivational basis of performance and well-being in two work settings. Journal of Applied Social Psychology, 34, 2045-2068.

Bakker, A. B., \& Demerouti, E. (2007). The job demands-resources model: State of the art. Journal of Managerial Psychology, 22, 309-328. doi:10.1108/02683940710733115.

Bidee, J., Vantilborgh, T., Pepermans, R., Huybrechts, G., Willems, J., Jegers, M., \& Hofmans, J. (2012). Autonomous motivation stimulates volunteers' work effort: A self-determination theory approach to volunteerism. Voluntas. Advance online publication. doi:10.1007/s11266-012-9269-x.

Cable, D. M., \& DeRue, D. S. (2002). The convergent and discriminant validity of subjective fit perceptions. Journal of Applied Psychology, 87, 875-884. doi:10.1037//0021-9010.87.5. 875.

Colarelli, S. M. (1984). Methods of communication and mediating processes in realistic job previews. Journal of Applied Psychology, 69, 633-642.

Deci, E. L., Eghrari, H., Patrick, B. C., \& Leone, D. R. (1994). Facilitating internalization: The self-determination theory perspective. Journal of Personality, 62, 119-142.
Deci, E. L., Koestner, R., \& Ryan, R. M. (1999). A meta-analytic review of experiments examining the effects of extrinsic rewards on intrinsic motivation. Psychological Bulletin, 125, 627-668.

Deci, E. L., \& Ryan, R. M. (1985). Intrinsic motivation and selfdetermination in human behavior. New York: Plenum.

Deci, E. L., \& Ryan, R. M. (2000). The "what" and "why" of goal pursuits: Human needs and the self-determination of behavior. Psychological Inquiry, 11, 227-268.

Deci, E. L., \& Ryan, R. M. (2008). Facilitating optimal motivation and psychological well-being across life's domains. Canadian Psychology, 49, 14-23. doi:10.1037/0708-5591.49.1.14.

Fernet, C. (2011). Development and validation of the work role motivation scale for school principals (WRMS-SP). Educational Administration Quarterly, 47, 307-331. doi:10.1177/001 $3161 X 10385108$.

Fernet, C., Guay, F., \& Senécal, C. (2004). Adjusting to job demands: The role of work self-determination and job control in predicting burnout. Journal of Vocational Behavior, 65, 39-56. doi:10. 1016/S0001-8791(03)00098-8.

Fernet, C., Guay, F., Senécal, C., \& Austin, S. (2012). Predicting intraindividual changes in teacher burnout: The role of perceived school environment and motivational factors. Teaching and Teacher Education, 28, 514-525. doi:10.1016/j.tate.2011.11. 013.

Gagné, M., Chemolli, E., Forest, J., \& Koestner, R. (2008). A temporal analysis of the relation between organisational commitment and work motivation. Psychologica Belgica, 48, 219-241.

Gagné, M., \& Deci, E. L. (2005). Self-determination theory and work motivation. Journal of Organizational Behavior, 26, 331-362. doi:10.1002/job.322.

Gagné, M., Forest, J., Gilbert, M.-H., Aubé, C., Morin, E., \& Malorni, A. (2010). The Motivation at Work Scale: Validation evidence in two languages. Educational and Psychological Measurement, 70, 628-646. doi:10.1177/0013164409355698.

Gagné, M., Forest, J., Vansteenkiste, M., Crevier-Braud, L., Van den Broeck, A., Aspeli, A. K., et al. (2012). Cross-cultural evidence for self-determination theory applied to the work domain. Unpublished manuscript, Concordia University, Montreal, Canada.

Gagné, M., Senécal, C. B., \& Koestner, R. (1997). Proximal job characteristics, feelings of empowerment, and intrinsic motivation: A multidimensional model. Journal of Applied Social Psychology, 27, 1222-1240.

Gillet, N., Gagné, M., Sauvagère, S., \& Fouquereau, E. (2013). The role of supervisor autonomy support, organizational support, and autonomous and controlled motivation in predicting employees' satisfaction and turnover intentions. European Journal of Work and Organizational Psychology, 22, 450-460. doi:10.1080/ 1359432X.2012.665228.

Greguras, G. J., \& Diefendorff, J. M. (2009). Different fits satisfy different needs: Linking person-environment fit to employee commitment and performance using self-determination theory. Journal of Applied Psychology, 94, 465-477. doi:10.1037/ a0014068.

Hackman, J. R., \& Oldham, G. R. (1976). Motivation through the design of work: Test of a theory. Organizational Behavior and Human Performance, 16, 250-279.

Humphrey, S. E., Nahrgang, J. D., \& Morgeson, F. P. (2007). Integrating motivational, social, and contextual work design features: A meta-analytic summary and theoretical extension of the work design literature. Journal of Applied Psychology, 92, 1332-1356. doi:10.1037/0021-9010.92.5.1332.

Jang, H., Kim, E. J., \& Reeve, J. (2012). Longitudinal test of selfdetermination theory's motivation mediation model in a naturally occurring classroom context. Journal of Educational Psychology, 104, 1175-1188. doi:10.1037/a0028089. 
Kuvaas, B. (2009). A test of hypotheses derived from self-determination theory among public sector employees. Employee Relations, 31, 39-56. doi:10.1108/01425450910916814.

Lam, C. F., \& Gurland, S. T. (2008). Self-determined work motivation predicts job outcomes, but what predicts selfdetermined work motivation? Journal of Research in Personality, 42, 1109-1115. doi:10.1016/j.jrp.2008.02.002.

Lauver, K. J., \& Kristof-Brown, A. (2001). Distinguishing between employees' perceptions of person-job and person-organization fit. Journal of Vocational Behavior, 59, 454-470.

Losier, G. F., \& Koestner, R. (1999). Intrinsic versus identified regulation in distinct political campaigns: The consequences of following politics for pleasure versus personal meaningfulness. Personality and Social Psychology Bulletin, 25, 287-298.

Millette, V., \& Gagné, M. (2008). Designing volunteers' tasks to maximize motivation, satisfaction and performance: The impact of job characteristics on volunteer engagement. Motivation and Emotion, 32, 11-22. doi:10.1007/s11031-007-9079-4.

Moreau, E., \& Mageau, G. A. (2011). The importance of perceived autonomy support for the psychological health and work satisfaction of health professionals: Not only supervisors count, colleagues too! Motivation and Emotion. Advance online publication. doi:10.1007/s11031-011-9250-9.

Morgeson, F. P., \& Humphrey, S. E. (2006). The Work Design Questionnaire (WDQ): Developing and validating a comprehensive measure for assessing job design and the nature of work. Journal of Applied Psychology, 91, 1321-1339. doi:10.1037/ 0021-9010.91.6.1321.

Niehoff, B. P., \& Moorman, R. H. (1993). Justice as a mediator of the relationship between methods of monitoring and organizational citizenship behavior. Academy of Management Journal, 36, 527-556.

Otis, N., \& Pelletier, L. G. (2005). A motivational model of daily hassles, physical symptoms, and future work intentions among police officers. Journal of Applied Social Psychology, 35, 2193-2214.

Pelletier, L. G., Fortier, M. S., Vallerand, R. J., \& Brière, N. M. (2001). Associations among perceived autonomy support, forms of self-regulation, and persistence: A prospective study. Motivation and Emotion, 25, 279-306.

Podsakoff, P. M., MacKenzie, S. B., Paine, J. B., \& Bachrach, D. G. (2000). Organizational citizenship behaviors: A critical review of the theoretical and empirical literature and suggestions for future research. Journal of Management, 26, 513-563.

Preacher, K. J., \& Hayes, A. F. (2008). Asymptotic and resampling strategies for assessing and comparing indirect effects in multiple mediator models. Behavior Research Methods, 40, 879-891. doi:10.3758/BRM.40.3.879.

Richer, S. F., Blanchard, C., \& Vallerand, R. J. (2002). A motivational model of work turnover. Journal of Applied Social Psychology, 32, 2089-2113.

Saks, A. M., \& Ashforth, B. E. (1997). A longitudinal investigation of the relationships between job information sources, applicant perceptions of fit, and work outcomes. Personnel Psychology, 50, 395-426.

Tremblay, M. A., Blanchard, C. M., Taylor, S., Pelletier, L. G., \& Villeneuve, M. (2009). Work Extrinsic and Intrinsic Motivation Scale: Its value for organizational psychology research. Canadian Journal of Behavioural Science, 41, 226-231. doi:10.1037/ a0015167.

Trépanier, S., Fernet, C., \& Austin, S. (2013). The moderating role of autonomous motivation in the job demands-strain relation: A two sample study. Motivation and Emotion, 37, 93-105. doi:10. 1007/s11031-012-9290-9.

Van Beek, I., Hu, Q., Schaufeli, W. B., Taris, T. W., \& Schreurs, B. H. J. (2012). For fun, love, or money: What drives workaholic, engaged, and burned-out employees at work? Applied Psychology: An International Review, 61, 30-55. doi:10.1111/j.14640597.2011.00454.x.

Van Beek, I., Taris, T. W., \& Schaufeli, W. B. (2011). Workaholic and work engaged employees: Dead ringers or worlds apart? Journal of Occupational Health Psychology, 16, 468-482. doi:10.1037/a0024392.

Van den Broeck, A., Vansteenkiste, M., De Witte, H., Soenens, B., \& Lens, W. (2010). Capturing autonomy, competence, and relatedness at work: Construction and initial validation of the Workrelated Basic Need Satisfaction scale. Journal of Occupational and Organizational Psychology, 83, 981-1002. doi:10.1348/ 096317909 X481382.

Vansteenkiste, M., Niemiec, C. P., \& Soenens, B. (2010). The development of the five mini-theories of self-determination theory: An historical overview, emerging trends, and future directions. In T. Urdan \& S. Karabenick (Eds.), Advances in motivation and achievement: The decade ahead (Vol. 16, pp. 105-166). Bingley: Emerald.

Williams, G. C., Niemiec, C. P., Patrick, H., Ryan, R. M., \& Deci, E. L. (2009). The importance of supporting autonomy and perceived competence in facilitating long-term tobacco abstinence. Annals of Behavioral Medicine, 37, 315-324. doi:10. 1007/s12160-009-9090-y. 